\title{
IDENTIFICAÇÃO DAS ESPÉCIES ARBÓREAS DAS MATAS ESTACIONAIS DE INSELBERGUES, ATRAVÉS DE CARACTERES VEGETATIVOS.
}

\author{
Carla dos Santos ${ }^{1}$; Paulo Henrique Reis ${ }^{2}$; Flávio França ${ }^{3}$ e Efigênia de Melo ${ }^{4}$ \\ 1. Bolsista PIBIC/FAPESB, graduanda em agronomia, Universidade Estadual de Feira de Santana, email: \\ carla.mascarenhas@hotmail.com \\ 2. Graduando em Biologia, Universidade Estadual de Feira de Santana, email: p.henrique_bio@hotmail.com \\ 3.Orientador, DCBIO, Universidade Estadual de Feira de Santana, email: flaviofranca@ hotmail.com \\ 4.Participante do projeto, DCBIO,Universidade Estadual de Feira de Santana, email: efidemelo@hotmail.com
}

PALAVRAS CHAVE: Sistema de Classificação, Caracteres foliares, preservação

\section{INTRODUÇÃO}

Os inselbergues são considerados afloramentos rochosos e isolados entre extensas superfícies baixas e horizontalizadas, que se desenvolvem em rochas de origem ígnea. A flora dos inselbergues é determinada por alguns fatores, tais como a altitude, posição geográfica, geologia, diversidade de habitats e variáveis ambientais como o microclima.

A mata de base de um inselbergue no geral, possui uma vegetação classificada como Savana estépica arborizada, e geralmente é referida como Matas da Base, onde são caracterizadas por três ambientes distintos que são: orla externa, o interior, e a orla interna. A orla externa, tem a vegetação arbustivo-arbórea, com um solo arenoso; Já o interior, possui uma flora de maior porte, também tendo o solo arenoso; e a orla interna tem um porte arbustivo com um solo mais raso (França \& Melo, 2014).

O conhecimento da composição florística é uma estratégia importante para preservação e conservação dessas áreas, além de colaborar com os estudos fitossociológicos desenvolvidos na região. Nestes estudos é muito comum a coleta de grande número de espécimes estéreis (sem flor e/ou sem fruto), dificultando a identificação e levando ao acúmulo de exemplares indeterminados no herbário.

O objetivo desse trabalho foi a elaborar de uma chave de identificação baseada em catacteres vegetativos de espécies arbóreas na mata da base de um inselbergue .

\section{MATERIAL E MÉTODOS}

A coleta foi realizada em uma mata na fazenda chapada, que está situada em Feira de Santana, Bahia. Foram feitas seis expedições a campo para coleta utilizando o método ponto quadrante o que totalizou em um registro de 400 espécimes.

Foram coletadas apenas amostras de arbustos e árvores estéreis ou não com a altura superior a $1,5 \mathrm{~m}$ altura e diâmetro da base acima de $3 \mathrm{~cm}$. Os seus devidos dados foram registrados em planilhas.

Foram aplicados os procedimentos tradicionais de coletas botânicas, que consistem na coleta e prensagem de amostras de plantas feitas com o auxilio de tesoura de poda. Foram feitos cortes nas plantas com tesoura de poda, colocadas em papel de coleta com o devido número do coletor, depois as plantas foram processadas e colocadas na estufa para secagem a $60^{\circ} \mathrm{C}$ (Mori et al., 1989). 
Após a secagem, foi feita a montagem das exsicatas com suas devidas etiquetas as quais contém informações da localidade e características do exemplar. Posteriormente as características vegetativas foram utilizadas para a elaboração do sistema de classificação baseado em folhas. Os seguintes caracteres foram utilizados: filotaxia, estrutura do limbo foliar, forma do limbo, nervura, margem, ápice, indumento, presença de glândulas, estípulas, acúleos e espinhos, nectários extraflorais.

As exsicatas estão depositadas no laboratório de Taxonomia Vegetal da UEFS (TAXON) na Coleção de Folhas (CF).

A identificação das espécies foi feita utilizando os especialistas, a literatura especializada disponível e a comparação com exemplares depositados no HUEFS. O nome das famílias e suas respectivas espécies estão de acordo com a lista da flora do Brasil (2016).

\section{RESULTADOS E DISCUSSÕES}

Foram coletadas um total de 35 espécies, das quais, duas estão identificados apenas ao nível de família, duas apenas ao nível de gênero, 28 ao nível de espécie, e três ainda não foram identificados. As famílias mais encontradas foram FABACEAE (5) MYRTACEAE (5) EUPHORBIACEAE (4) BIGNONIACEAE (3) POLYGONACEAE (2) RUBIACEAE (2) PHYLLANTHACEAE (2) MALVACEAE (2) E ANACARDIACEAE (2). As demais famílias foram representadas por uma única espécie (TABELA 1).

A partir das categorias principais, foram acrescentadas subcategorias, com a intenção de cada espécie ter uma característica única. A terceira categoria foi a que obteve o maior número de espécies, o que resultou em um número maior de subcategorias para diferenciá-las. As espécies com maior dificuldade para distinguir foram Savia sessiliflora (Sw.) Willd., Flueggea schuechiana (Müll.Arg.) G.L.Webster (ambas PHYLLANTHACEAE), Maprounea guianensis Aubl., e Sebastiania brasiliensis Spreng. (ambas EUPHORBIACEAE).

Pelo fato dos caracteres vegetativos serem mais vastos que os reprodutivos, é importante ter cuidado ao escolher os ramos que forem analisados, pois influência do ambiente que pode alterar a real característica morfológica. Por isso o ideal para se ter uma chave mais eficaz, é dar preferência a ramos adultos e que não tenham interferências de doenças.

Chave para identificar as espécies da área de estudos: 
1-Folha altema espiralada

2-Folhas simples

3-Folha glabra

4-Limbo ovado

5-Apice obtuso

Casearialuetzelburgï Sleumer

5-Ápice não obtuso

4-Limbo não ovado

6-Ápice emarginado

6a-Nervação conspicua.

Coccoloba alnifolia

6b-Nervação inconspícu . (indeterminada 1)

6-Apice não emarginado

7-Folha concolor

8-Estípula presente

9-Margem crenada

9-Margem não crenada

9 a-Base cordada auriculada

(indeterminada 2 )

9 b-Base não cordada auriculada Acanthocladus albicans A. W. Been

8-Estípula ausente

7-Folha discolor

10-Estípula pontuda

10-Estípula nãopontuda

11-Presença da cicatriz da ócrea

11-Ausência da cicatriz da ócrea

3-Folha comindumento

12-Com espinhos.

12-Sem espinhos

13-Margem serreada

13-Margemnão serreada

14-Folha concolor

14-Folha discolor.

2 Folhas compostas

15-Folha imp aripinada

16-Margeminteira

17-Folha digitada

17-Folha não digitada

18-Mais de 4 nervuras secundarias por $\mathrm{cm}$

18 -Menos de 4 nervuras secundárias por $\mathrm{cm}$

$18 \mathrm{a}$ - Folíolo assimétrico

$18 \mathrm{~b}$-Foliolo simétrico

$18 \mathrm{~b} 1$-Foliolo teminal maior que $10 \mathrm{~cm}$

$18 \mathrm{~b} 2$-Foliolo teminal menor que $10 \mathrm{~cm}$

16-Margem serreada

15-Folha paripinada

19-Folha bifoliolada

19-Folha multifoliola da

20-Folha tetrafoliolada

20-Folha commais de 4 foliolos

21-Folha não recomposta

21-Folha recomposta

1 Filotaxia oposta ou verticilada

21-Folha verticilada

21-Folha oposta

22-Folha composta

24-Folha trifoliola da

24-Folha pentafoliolada

25-Foliolo com margem serreada

25-Foliolo com margem inteira

Ceibaglaciovii

Capsicuon caatingae

Maprounea guianensis

....... (indeterminada 3)

Sebastiania brasiliensis

Flueggea schuechiano

Ruprechtia laxiflora Savia sessiliflora

Ximenia americana

Sidastrom paniculatum

-Folha simples

26-Folha compontuações translúcidas

27-Apice da follha obtuso-emarginado

27-Ápice não emarginado

28-Margem não revoluta

Spondias mombin

28-Margemrevoluta

29-Nervação secundária inconspicua

29-Nervação secundária conspícua

30-Margem plana, limbo conáceo

30-Margem ondulada, limbo membranáceo

Poincianela piramydalis

ABACEAE (indeterminada) Cupaniaoblongifolia

Bauhinialongifolia

Goniorrhachis marginato

Poincianella laxiflora

Parapiptadeniarigida

Handroanthus riodocensis

Handroanthus serratifolits

Handroanthus impetiginosus

6-Folhas sem portuações transhúcidas

Eugenia sp.2

Eugenia mollicoma

Eugenialigustrina

Eugeniasp. 1

Campomanesiaeugenioides

RUBIACEAE 


\section{CONCLUSÕES}

Essa chave não é indicada para ser utilizada em outras áreas pois pode existir uma variação morfológica influenciada pelo ambiente, o que muito provavelmente causará insucesso na identificação das espécies.

É muito difícil identificar as espécies com base em caracteres vegetativos pelo fato de que muitas destas características se sobrepõe em diferentes famílias, o que justifica o fato de algumas espécies terem permanecido indeterminadas até o momento.

\section{REFERÊNCIAS}

BATALHA, M. A.; ARAGAKI, S.; MANTOVANI, W. Chave de identificação das espécies vasculares do cerrado em Emas (Pirassununga, SP) baseada em caracteres vegetativos. Boletim de Botânica da Universidade de São Paulo, p. 85-108, 1988.

CARVALHO, M. Florística e estrutura fitossociológica da floresta na base de inselbergues no semiárido da Bahia. Indicação de espécies para sua recuperação. Dissertação de Mestrado. Feira de Santana: UEFS/PPGRGV, 2014.

FRANÇA, FLÁVIO; MELO, E. Flora de inselbergues no semiárido da Bahia : Região de Milagres e adjacências. $1^{\circ}$ Edição. Feira de Santana: Universidade Estadual de Feira de Santana, 2014

MORI, SCOTT; MATTOS-SILVA, LUIZ; LISBOA, GILDRO, CORADIN, LÍDIO. Manual de Manejo do Herbário fanerogâmico. Ilhéus: CEPLAC, 1989 